\title{
U.K. Climate Projections: Summer Daytime and Nighttime Urban Heat Island Changes in England's Major Cities
}

\author{
Y. T. Eunice Lo, ${ }^{\mathrm{a}}$ Daniel M. Mitchell, ${ }^{\mathrm{a}}$ Sylvia I. Bohnenstengel, ${ }^{\mathrm{b}}$ Mat Collins, ${ }^{\mathrm{c}}$ Ed Hawkins, ${ }^{\mathrm{d}, \mathrm{e}}$ \\ Gabriele C. Hegerl, ${ }^{\mathrm{f}}$ Manoj Joshi, ${ }^{\mathrm{g}}$ AND Peter A. StotT ${ }^{\mathrm{h}, \mathrm{c}}$ \\ ${ }^{a}$ School of Geographical Sciences, University of Bristol, Bristol, United Kingdom; ${ }^{b}$ MetOffice@Reading, Department of \\ Meteorology, University of Reading, Reading, United Kingdom; ${ }^{c}$ College of Engineering, Mathematics and Physical Sciences, \\ University of Exeter, Exeter, United Kingdom; ${ }^{d}$ National Centre for Atmospheric Science, University of Reading, Reading, United \\ Kingdom; ${ }^{e}$ Department of Meteorology, University of Reading, Reading, United Kingdom; ${ }^{f}$ School of Geosciences, University of \\ Edinburgh, Edinburgh, United Kingdom; ${ }^{g}$ Climatic Research Unit, School of Environmental Sciences, University of East Anglia, \\ United Kingdom; ${ }^{h}$ Met Office Hadley Centre, Exeter, United Kingdom
}

(Manuscript received 19 December 2019, in final form 17 June 2020)

\begin{abstract}
In the United Kingdom, where $90 \%$ of residents are projected to live in urban areas by 2050 , projecting changes in urban heat islands (UHIs) is essential to municipal adaptation. Increased summer temperatures are linked to increased mortality. Using the new regional U.K. Climate Projections, UKCP18-regional, we estimate the 1981-2079 trends in summer urban and rural near-surface air temperatures and in UHI intensities during day and at night in the 10 most populous built-up areas in England. Summer temperatures increase by $0.45^{\circ}-0.81^{\circ} \mathrm{C}$ per decade under RCP8.5, depending on the time of day and location. Nighttime temperatures increase more in urban than rural areas, enhancing the nighttime UHI by $0.01^{\circ}-0.05^{\circ} \mathrm{C}$ per decade in all cities. When these upward UHI signals emerge from 2008-18 variability, positive summer nighttime UHI intensities of up to $1.8^{\circ} \mathrm{C}$ are projected in most cities. However, we can prevent most of these upward nighttime UHI signals from emerging by stabilizing climate to the Paris Agreement target of $2^{\circ} \mathrm{C}$ above preindustrial levels. In contrast, daytime UHI intensities decrease in nine cities, at rates between $-0.004^{\circ}$ and $-0.05^{\circ} \mathrm{C}$ per decade, indicating a trend toward a reduced daytime UHI effect. These changes reflect different feedbacks over urban and rural areas and are specific to UKCP18-regional. Future research is important to better understand the drivers of these UHI intensity changes.
\end{abstract}

KEYWORDS: Atmosphere-land interaction; Climate change; Temperature; Climate models; Trends

\section{Introduction}

Increased exposure to high temperatures and, therefore, increased levels of heat-related mortality are projected in a warming world (Lo et al. 2019; Vicedo-Cabrera et al. 2018). Urban inhabitants are generally more susceptible to heat stress due to the urban heat island effect (Fischer et al. 2012; Heaviside et al. 2016). An urban heat island is characterized by higher nearsurface air or surface skin temperatures in a given urban area compared to its rural surroundings. This study focuses on the air urban heat island (UHI) effect because it has direct relevance to heat stress.

Urban areas tend to be densely built with structures such as buildings and paved roads. Narrow streets flanked by tall buildings on both sides are a common sight, forming urban canyons that have large surface areas for daytime heat absorption (Kershaw et al. 2010). Construction materials such as concrete and asphalt have low albedo. The thermal properties and large surface areas of urban structures lead to a high thermal inertia (Erell and Williamson 2007; Bohnenstengel et al. 2011), meaning that urban structures absorb and store heat during the day and release it at night (Yamamoto 2006; Kershaw et al. 2010; Schlünzen and Bohnenstengel 2016). With densely built structures, urban areas tend to lack vegetation. On the contrary, rural areas tend to be less densely built than urban areas. Natural land covered in soil and vegetation has

Corresponding author: Y. T. Eunice Lo, eunice.lo@bristol.ac.uk lower thermal inertia, higher albedo and often more moisture than urban areas. These urban/rural differences tend to lead to the formation of a UHI.

During the day, net incoming solar radiation increases heat storage in the urban canopy. The stored heat leads to an upward directed sensible heat flux that warms the urban boundary layer once surface temperatures exceed air temperatures. With lower thermal inertia, the upward sensible heat flux increases earlier in the day in rural areas (Oke 1987; Kershaw et al. 2010; Sachindra et al. 2016; Bohnenstengel et al. 2011). At night, the urban environment maintains a positive upward sensible heat flux until urban surface temperatures drop below air temperatures. On the other hand, the sensible heat flux in the rural surroundings quickly decreases due to their small thermal inertia. This phase shift in sensible heat flux is one of the causes of air temperature differences between urban and rural areas (Bohnenstengel et al. 2011, 2014).

Paved surfaces and reduced vegetation in urban areas limit latent heat loss through evapotranspiration, increasing the upward sensible heat flux that warms the urban boundary layer (Oke 1987; Kershaw et al. 2010). Moreover, urban canyons increase roughness and reduce average wind speeds, reducing total turbulent heat loss (Oke 1987; Wilby 2003). In addition, anthropogenic heat from energy use, traffic and industrial processes (Bohnenstengel et al. 2014; Allen et al. 2011), and urban air pollution can contribute to a UHI depending on the time of day (Oke 1987; Wilby 2003). 
The UHI effect has been observed around the world (Sachindra et al. 2016; Wilby 2003; Cui and De Foy 2012; Basara et al. 2010; Tan et al. 2010; Erell and Williamson 2007). It is most pronounced under clear skies and low wind conditions, when urban/rural differences in stored energy, net longwave radiation loss, and turbulent heat loss are greatest (Oke 1987; Erell and Williamson 2007). The UHI effect is commonly quantified by the UHI intensity, which in this study is the near-surface air temperature difference between an urban site and a rural site. In the United Kingdom, UHI intensities of over $7^{\circ} \mathrm{C}$ in central London (Wilby 2003), up to $5^{\circ} \mathrm{C}$ in Manchester (Smith et al. 2011), and nearly $5^{\circ} \mathrm{C}$ in Birmingham (Heaviside et al. 2015) were recorded during summer periods. All these observation-based studies reported maximum UHI intensities at night, revealing a diurnal cycle of the UHI effect that is consistent with the literature (Oke 1987).

Using climate model simulations, Fischer et al. (2012) showed that summer urban air tended to be warmer and drier than rural air in regions including northern Europe. The effect of this was a positive urban/rural contrast in heat stress that was most pronounced at night, highlighting the risk of heat-related morbidity and mortality in urban population. Indeed, $52 \%$ of heat-related deaths in the West Midlands (United Kingdom), during the August 2003 heatwave could be attributed to the UHI effect (Heaviside et al. 2016). An increase in high heat stress occurrences (Fischer et al. 2012) and mortality (Heaviside et al. 2016) is projected for urban areas in a warming climate.

Apart from heat stress, UHIs can induce mesoscale atmospheric circulations, typically characterized by convergence in the lower part of the planetary boundary layer and divergence in the upper part if a UHI is positive (Zhang et al. 2014). The strength of a UHI-induced circulation depends on the UHI intensity and background wind conditions. Vukovich et al. (1979) reported high surface ozone concentrations in the zone of convergence when UHI circulation persisted in St. Louis, Missouri, demonstrating links between UHIs and the formation and concentration of this air pollutant (Lee 1979). In Paris, Sarrat et al. (2006) concluded that the UHI significantly modified the spatial distribution and availability of ozone and nitrogen oxide during an anticyclonic episode in 1999. Indeed, links between UHI-induced mesoscale winds and severe air pollution in urban areas were supported by mathematical modeling (Agarwal and Tandon 2010). Conversely, mitigation of the UHI in Stuttgart, Germany, was found to reduce vertical dilution of urban primary pollutants such as nitric oxide and carbon monoxide, increasing their concentrations (Fallmann et al. 2016). Air pollution has a potential confounding effect on heat-related mortality (Rainham and Smoyer-Tomic 2003).

In a warming climate, projected increases in urban and rural temperatures would affect human heat stress and potentially the effect of UHI. Such changes need to be quantified because $68 \%$ of the world's population (UN DESA 2018) and $90 \%$ of the United Kingdom's population (UN DESA/Population Division 2018) are projected to live in urban areas by 2050. Using extrapolation and statistical downscaling techniques, studies estimated an increase in UHI intensity to $2.4^{\circ} \mathrm{C}$ in Manchester, by the end of this century (Levermore et al. 2018) and a $0.5^{\circ} \mathrm{C}$ increase in summer nighttime UHI intensity in London between the 1960s and the 2050s (Wilby 2008). However, another study that coupled a regional climate model to an urban land surface scheme found a $0.1^{\circ} \mathrm{C}$ decrease in summer daytime UHI intensity and an unaltered summer nighttime UHI intensity in London between 1971-90 and 2041-60 (McCarthy et al. 2012).

The Met Office produces a new set of U.K. climate projections every few years to provide the most up-to-date assessment of climate change over the twenty-first century. Mainly designed for the United Kingdom and peer reviewed, these projections are one of the most reputable datasets available for the United Kingdom. While the previous generation, UKCP09, did not include urban effects (Murphy et al. 2009), the newest regional U.K. climate projections (UKCP18-regional) include an urban land surface type for the first time (Murphy et al. 2018 , 2009). This provides a new opportunity for us to assess future urban and rural temperature and UHI intensity changes in the United Kingdom. Here, we estimate trends in summer daytime and nighttime temperatures in urban and rural areas, as well as the resulting trends in UHI intensities in the 10 most populous built-up areas in England-Greater London, Greater Manchester, West Midlands, West Yorkshire, Liverpool, South Hampshire, Tyneside, Nottingham, Sheffield, and Bristol—in the period 1981-2079.

We investigate whether future summer urban and rural temperatures, and UHI intensities in these built-up areas would be statistically significantly different from their most recent (2008-18) values, taking climate variability into account. By estimating at what levels of global mean warming these changes in temperature or UHI intensity might emerge from variability, we compare our emergence results with the Paris Agreement's $1.5^{\circ}$ and $2^{\circ} \mathrm{C}$ temperature targets (UNFCCC 2015) and the $3^{\circ} \mathrm{C}$ warming above preindustrial levels that current nationally determined contributions (NDCs) may imply (Rogelj et al. 2016).

\section{Materials and methods}

\section{a. HadUK-Grid}

To examine the historical UKCP18-regional simulations of urban and rural temperatures and the UHI effect in England, we make use of the gridded climate observations for the United Kingdom, HadUK-Grid (Hollis et al. 2019). HadUK-Grid is a new collection of gridded datasets created by the Met Office based on meteorological station data. Datasets of various climate variables dating back to as early as the second half of the nineteenth century are available at horizontal resolutions of up to $1 \mathrm{~km}$. The reader is referred to Hollis et al. (2019) for the details of quality control and gridding of the data.

Because of a lack of subdaily temperature data from HadUKGrid and indeed UKCP18-regional, we investigate changes and trends in summer daytime and nighttime UHI intensities based on daily maximum and minimum air temperatures (tasmax and tasmin) in June, July, and August (JJA) throughout this study. We use the 1981-2017 JJA daily tasmax and tasmin data from HadUK-Grid at $12-\mathrm{km}$ resolution for direct comparison with UKCP18-regional and for bias correction. 


\section{b. UKCP18-regional}

UKCP18-regional is a set of climate simulations over a European domain $\left(20.51^{\circ}-66.89^{\circ} \mathrm{N}, 47.59^{\circ} \mathrm{W}-68.54^{\circ} \mathrm{E}\right)$ for the period 1980-2080, with projections beyond 2005 based on the RCP8.5 scenario (Murphy et al. 2018). Being a high-emissions scenario, RCP8.5 was chosen by the Met Office to identify climate change signals against natural variability in the near future. This way, climate risks can be assessed in a precautionary approach. UKCP18-regional has a horizontal resolution of $12 \mathrm{~km}$ that resolves finer features than its predecessor, UKCP09 (Murphy et al. 2009).

UKCP18-regional consists of 12 perturbed parameter ensemble members of the regional atmospheric model HadREM3-GA7-05, each of which was driven by the corresponding global simulation (at $60-\mathrm{km}$ resolution) of a new Met Office coupled atmosphere-ocean model, HadGEM3-GC3.05 (Murphy et al. 2018). This global climate model generally simulates higher global mean temperatures than the observations (Cowtan and Way 2014) for the period 2000-17 (Murphy et al. 2018). For future years, the HadGEM3-GC3.05 ensemble projects higher global mean temperatures than most selected CMIP5 models under RCP8.5 (Murphy et al. 2018; Taylor et al. 2012). This suggests a higher equilibrium climate sensitivity in the model, which can be explained by a weaker shortwave negative cloud feedback in the midlatitudes (Bodas-Salcedo et al. 2019).

The 12 UKCP18-regional ensemble members were selected by the Met Office based on criteria that maximized the ensemble spread in global aerosol forcing, climate feedback strength, and model parameters in the convection, gravity wave drag, boundary layer, cloud, aerosols, and land surface schemes (Murphy et al. 2018). The Met Office also validated the members' historical performance in European climatology, Atlantic meridional overturning circulation strength, and Northern Hemisphere surface temperature. Nevertheless, since they were all driven by HadGEM3-GC3.05, they sample the warmer end of probabilistic future projections as compared with CMIP5 (Murphy et al. 2018).

UKCP18-regional provides a new opportunity to study the urban effects on U.K. climate in the twenty-first century. Urban effects are represented as one of nine land surface types in the model. A tiling approach is used to calculate the surface energy balance separately for each subgrid-scale surface type in each grid box. An aggregated surface energy balance is then calculated based on these subgrid-scale fluxes (Best et al. 2011). The one-tile urban scheme in UKCP18-regional uses a bulk representation for urban areas by introducing a large thermal inertia, and it radiatively couples the urban surface and the soil (Best 2005). Although urban characteristics such as canopy heat capacity $\left(2.8 \times 10^{5} \mathrm{~J} \mathrm{~K}^{-1} \mathrm{~m}^{-2}\right)$ and roughness lengths for heat and momentum do not vary spatially in this scheme (Best et al. 2011), urban land cover fraction does.

Figure 1 shows the urban fraction in each $12-\mathrm{km}$ UKCP18-regional grid box covering England and Wales on the Ordnance Survey's British National Grid. These urban fractions do not change over time in the simulations. Grid boxes with elevated urban fractions are mainly located in the 10 most populous built-up areas (BUAs) in England and Wales
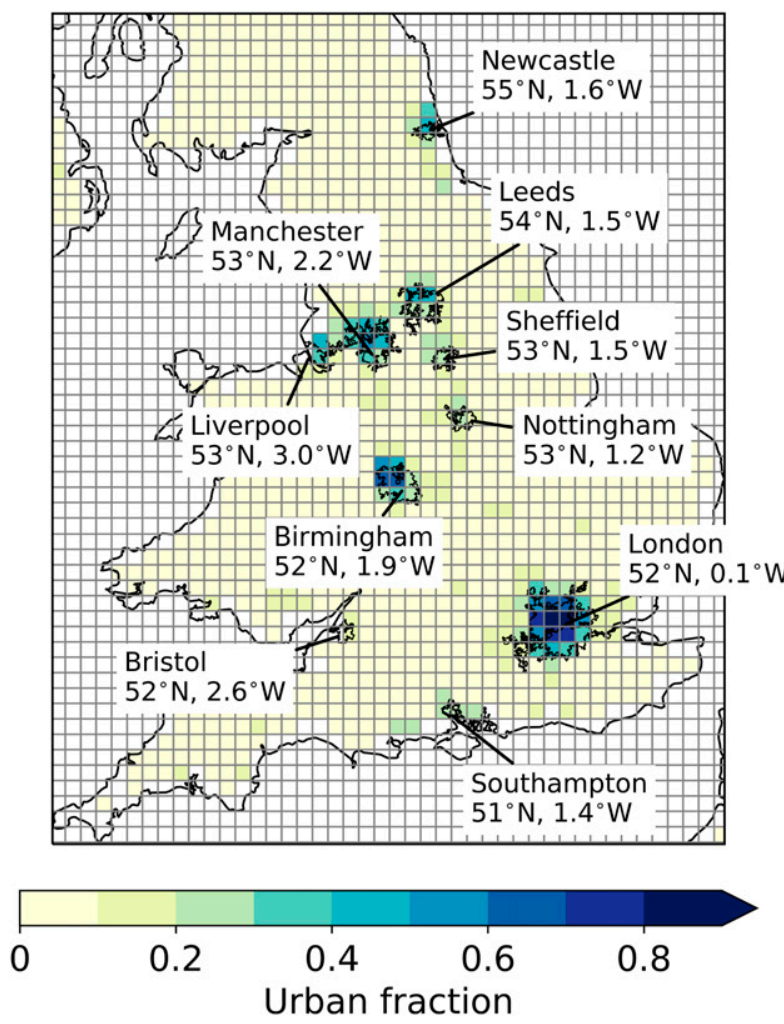

FIG. 1. Urban fraction in the $12-\mathrm{km}$ grids of the UKCP18regional simulations overlaid with the boundaries of the 10 most populous built-up areas in England, according to data from the Office for National Statistics. The urban fractions do not change between 1980 and 2080. The latitude and longitude of individual cities are indicated. This map is shown in the Ordnance Survey's British National Grid.

defined by the Office for National Statistics (Office for National Statistics 2013) (Fig. 1). We identify urban and rural grid boxes with the urban fractions and study the UHI effect in the BUAs shown in Fig. 1. Hereinafter, we refer to the BUAs by the main cities therein (city names and locations are indicated in Fig. 1). In descending order of 2016 population estimates, the included BUAs (cities) are Greater London (London), Greater Manchester (Manchester), West Midlands (Birmingham), West Yorkshire (Leeds), Liverpool (Liverpool), South Hampshire (Southampton), Tyneside (Newcastle), Nottingham (Nottingham), Sheffield (Sheffield), and Bristol (Bristol). See Table 1 for more details.

\section{c. EURO-CORDEX}

Although our main focus is the new UKCP18-regional simulations, we include UHI projections from the European branch of the Coordinated Regional Downscaling Experiment (EURO-CORDEX; Jacob et al. 2014) in section 4 to aid discussion of our results. EURO-CORDEX is an internationally coordinated framework that provides regional climate projections for the same European domain as UKCP18-regional. Regional climate models (RCMs) are driven by various CMIP5 global climate models (GCMs) within EURO-CORDEX, producing 
TABLE 1. The 10 most populous built-up areas and the cities therein included in this study, listed in descending order of their 2016 population estimates (not shown) (Office for National Statistics 2013). The rightmost two columns show the urban fractions in urban and rural grid boxes in each area.

\begin{tabular}{llccr}
\hline \multicolumn{1}{c}{ BUA } & \multicolumn{1}{c}{ City } & BUA size $\left(\mathrm{km}^{2}\right)$ & Highest urban fractions (urban) & Lowest urban fractions (rural) \\
\hline Greater London & London & 1737.9 & $0.88,0.92$ & $0.06,0.07$ \\
Greater Manchester & Manchester & 630.3 & $0.48,0.59$ & $0.04,0.04$ \\
West Midlands & Birmingham & 598.9 & $0.64,0.64$ & $0.02,0.02$ \\
West Yorkshire & Leeds & 487.8 & $0.42,0.48$ & $0.01,0.01$ \\
Liverpool & Liverpool & 199.6 & $0.36,0.41$ & $0.01,0.03$ \\
South Hampshire & Southampton & 192.0 & $0.24,0.27$ & $0.00,0.00$ \\
Tyneside & Newcastle & 180.5 & $0.33,0.43$ & $0.00,0.00$ \\
Nottingham & Nottingham & 176.4 & $0.23,0.27$ & $0.00,0.00$ \\
Sheffield & Sheffield & 167.5 & $0.26,0.27$ & $0.00,0.00$ \\
Bristol & Bristol & 144.4 & $0.16,0.16$ & $0.00,0.00$ \\
\hline
\end{tabular}

climate data at 50 - and $\sim 12-\mathrm{km}$ horizontal resolutions under different scenarios including RCP8.5 (Jacob et al. 2014).

Here, we use daily historical and RCP8.5 simulations of tasmax and tasmin at $12-\mathrm{km}$ resolution from the GCM-RCM pairs from three modeling groups: the Met Office Hadley Centre (MOHC), the Institut Pierre-Simon Laplace (IPSL), and the Max-Planck-Institut für Meteorologie (MPI-M). The included RCMs are MOHC's HadREM3-GA7-05, IPSL's WRF381P, and MPI-M's REMO2009 (Jacob et al. 2012). These RCMs are respectively driven by HadGEM2-ES (Jones et al. 2011), IPSL-CM5A-MR (Dufresne et al. 2013), and MPI-ESMLR (Giorgetta et al. 2013). The MOHC and IPSL models have one simulation each, whereas the MPI-M model has two ensemble members.

\section{d. UHI intensity}

We define UHI intensity as the near-surface air temperature (at $1.5 \mathrm{~m}$ ) difference between urban and rural grid boxes in the same area. For each included city, we define a 5-gridbox by 5-gridbox outer box centered on its city center, the location of which is indicated in Fig. 1. Based on the urban fractions in UKCP18-regional as shown in Fig. 1, the two grid boxes with the highest urban fractions in this box are identified as urban, whereas the two grid boxes with the lowest urban fractions are identified as rural. We use this definition because it can be applied to all chosen cities even though they have substantially different sizes and degrees of urbanization (Fig. 1). Table 1 lists the urban fractions in the selected grid boxes for all cities. All urban grid boxes have an urban fraction higher than 0.15 , whereas all rural grid boxes have an urban fraction substantially lower than this threshold. Since the rural grid boxes in the top five cities are not entirely rural (urban fraction $=0$ ), we may be underestimating the UHI intensity in the largest cities.

For each included city, the urban temperature $T_{\text {urban }}$ is the average temperature across the two urban grid boxes; the rural temperature $T_{\text {rural }}$ is the average temperature across the two rural grid boxes. The UHI intensity of a city $\left({ }^{\circ} \mathrm{C}\right)$ is given thus: UHI intensity $=T_{\text {urban }}-T_{\text {rural }}$. Representing urban areas by two grid boxes overestimates the size of the smaller cities (Table 1), so we may be underestimating the UHI intensity in these cities. Using one or six grid boxes instead of two does not alter our main results (not shown).
We focus on summer months (JJA) because these are months during which heatwaves happen. We also investigate how UHI intensity may change in each city on its annual three consecutive warmest days - that is, the three consecutive days over which average daily tasmax is the highest among all 3-day periods in a year in each 5 -gridbox by 5 -gridbox square centered on a city center (see above). Identifying warmest periods via tasmax over three consecutive days is similar to the Met Office's official definition of a heatwave (Met Office 2019). We assume the warmest days in the 5 -gridbox by 5 -gridbox squares are representative of the warmest days over individual urban and rural grid boxes therein (Fenner et al. 2019).

For each year in 1981-2079 and for each ensemble member, we calculate the average summer (JJA) and "warmest days" daytime and nighttime UHI intensities from daily tasmax and tasmin in identified urban and rural grid boxes. We also compute the ensemble averages. We find trends in daytime and nighttime $T_{\text {urban, }}, T_{\text {rural }}$, and UHI intensities by linearly regressing the annual temperature or UHI intensity values against year via ordinary least squares regression.

\section{e. Bias correction}

Although the 12 UKCP18-regional ensemble members simulate higher global mean temperatures than the observations (section 2b), on average they simulate lower JJA tasmax and tasmin but larger warming trends than HadUK-Grid for most of the United Kingdom in 1981-2017 (Fig. 2). Exceptions are in tasmin in southeast England and northwest Scotland, where the UKCP18-regional ensemble-mean temperatures are higher than the observed values in HadUK-Grid. The cool biases in summer temperatures in most parts of the United Kingdom are consistent with the Met Office's evaluation of the model against the National Climate Information Centre's data from 1981-2000 (Murphy et al. 2018), and they are associated with increased cloud cover in the regional model (Murphy et al. 2018).

The 12-member UKCP18-regional ensemble adequately samples HadUK-Grid temperatures except for tasmin in the London area and tasmax in Scotland (hatching in Fig. 2 indicates areas where HadUK-Grid falls outside the UKCP18regional ensemble spread). However, different model biases between urban and rural grid boxes lead to biases in UHI 
UKCP18 - HadUK-Grid, 1981-2017 JJA
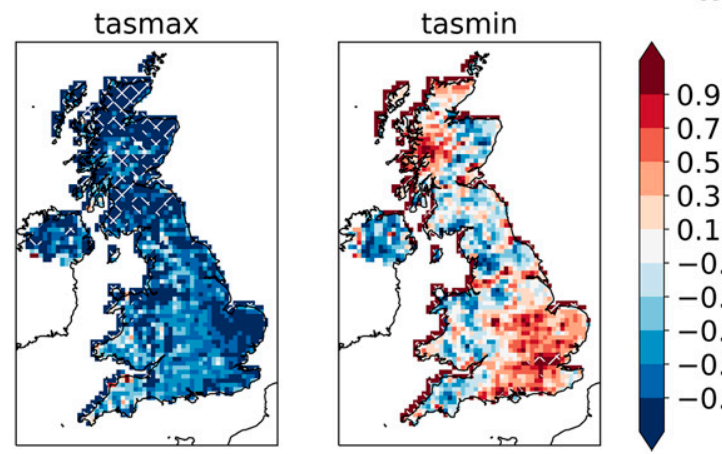

0.7

$-0.5$

0.3

$0.1 \cup$

$-0.1^{\circ}$

$-0.3$

$-0.5$

$-0.7$

$-0.9$ tasmax trend

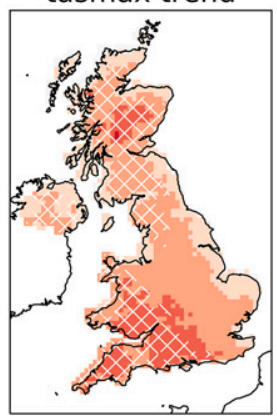

tasmin trend

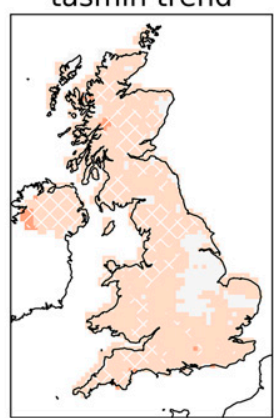

0.9

$-0.7$

0.5

0.3

0.1

$-0.1$ $-0.3 \stackrel{1}{2}$ $-0.5 \cup$ $-0.7^{\circ}$

$-0.9$
FIG. 2. Differences between UKCP18-regional ensemble mean and HadUK-Grid over summers (JJA) in 1981-2017, showing (top) biases in average daily (left) maximum and (right) minimum temperatures and (bottom) biases in their trends in degrees Celsius per decade. Hatching indicates areas where HadUK-Grid falls outside the UKCP18-regional ensemble range.

intensity. For example, a smaller cool bias in tasmax and a larger warm bias in tasmin in central London relative to its surroundings (Fig. 2) lead to an overestimation of both daytime and nighttime UHI intensities in London (Figs. 3 and 4). Indeed, UKCP18-regional generally overestimates summer UHI intensities in the cities of interest in 1981-2017, with nighttime UHI biases more pronounced than daytime biases (Figs. 3 and 4).

To bias correct, we find the offset in 1981-2017 mean JJA tasmax and tasmin between HadUK-Grid and each UKCP18regional ensemble member in each grid box. Assuming these offsets do not change over time, we add them to the corresponding tasmax and tasmin simulations in UKCP18-regional for the whole period of 1981-2079. In other words, we shift the mean temperature and, therefore, UHI intensity in individual UKCP18-regional ensemble members to match the 1981-2017 mean in HadUK-Grid. Correcting only the mean is reasonable here because (i) the biases in daytime and nighttime UHI intensities in UKCP18-regional appear to be close to constant over time in 1981-2017 (Figs. 3 and 4), and (ii) the standard deviations in tasmax and tasmin are similar between HadUKGrid and UKCP18-regional (not shown). All UKCP18-regional results in the remainder of this study are based on biascorrected data.
By removing the mean bias in temperature, we preserve the raw UHI trends in UKCP18-regional. All members of the UKCP18-regional ensemble underestimate the summer daytime UHI trend for Liverpool, Southampton, Newcastle, and Bristol and overestimate the trend for Nottingham in 19812017 (bottom-left panel of Fig. 5). For nighttime UHI, the whole UKCP18-regional ensemble overestimates the trend for Birmingham (bottom-right panel of Fig. 5). These biases should be taken into account when interpreting the trend results for these cities.

The EURO-CORDEX models simulate a wide range of UHI intensity averages and trends in the period 1981-2017 (Fig. 5), showing larger biases than UKCP18-regional in some cases. We do not bias-correct EURO-CORDEX tasmax and tasmin here as we are only interested in their UHI trends, which are unaffected by removing the mean bias.

\section{f. Emergence of temperature and UHI signals}

To find year of emergence of temperature or UHI signals in UKCP18-regional, we use the most recent period, 2008-18, as a reference and construct a sample of 132 temperature or UHI intensity values $(12$ ensemble members $\times 11$ years $)$. We then move the analysis period forward by one year at a time, comparing the new sample of temperatures or UHI intensities to the reference sample using the Kolmogorov-Smirnov test (K-S test), akin to Mahlstein et al.'s (2012) and King et al.'s (2015) approach to estimating the time of emergence of local warming signals and climate extremes. The advantage of the K-S test is that it is sensitive to differences in both the location and shape of two samples. We compare the new sample of each subsequent period (up until 2069-79) with that of the reference period in the same way and record all resulting significance $p$ values. The middle year of the period in which the $p$ value drops and remains below 0.05 is taken as the year of emergence.

We also express emergence of temperature and UHI intensity signals in terms of the amount of global mean warming since 2008-18 in the global simulations of UKCP18 (UKCP18global), at the time when the temperature and UHI values become statistically significantly different from the 2008-18 values at the $5 \%$ significance level. In other words, we find the amount of global mean warming since 2008-18 in the year of emergence and refer to it as "global mean warming of emergence." We choose 2008-18 as reference because it is the period closest in time to the present that would have been validated against observations by the Met Office. Using the ensemble average of UKCP18-global $(60 \mathrm{~km})$ monthly mean temperature simulations, we find the amount of global mean warming since $2008-18$ for each period between $2008-18$ and 2069-79. Global mean warming of emergence is the amount of global mean warming between 2008-18 and the period of emergence (when $p$ value drops and remains below 0.05 ).

To put global mean warming of emergence into the context of the Paris Agreement, we estimate the amount of global mean warming between the preindustrial period (1850-1900) and 2008-18 using the observational dataset HadCRUT4-CW (Cowtan and Way 2014). This dataset is based on Hadley Centre/Climatic Research Unit version 4 (HadCRUT4) 


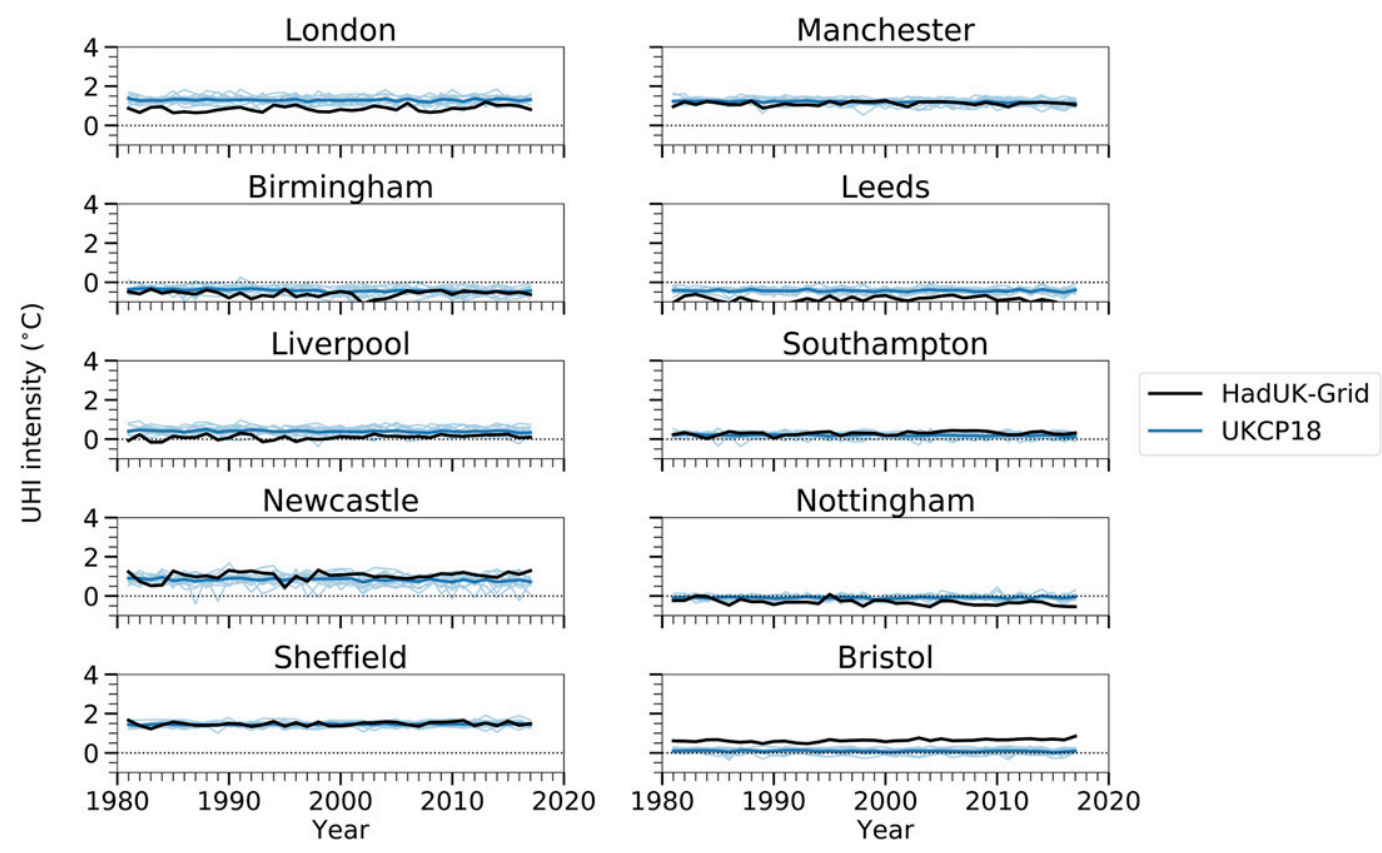

FIG. 3. Time evolution of summer (JJA) daytime UHI intensities in HadUK-Grid (black line) and the UKCP18regional simulations (blue lines) during 1981-2017. Thick blue lines indicate UKCP18-regional ensemble means, and thin blue lines indicate individual ensemble members.

(Morice et al. 2012), but with missing values in HadCRUT4 filled by kriging (Cowtan and Way 2014). HadCRUT4-CW is more consistent with the UKCP18-global temperature simulations than HadCRUT4 (Murphy et al. 2018). We use HadCRUT4-CW to estimate global mean warming between preindustrial times and the most recent decade because UKCP18- global does not cover the preindustrial period. We find a global mean warming of $0.97^{\circ} \mathrm{C}$ between $1850-1900$ and $2008-18$ from HadCRUT4-CW. This value is within the range of $0.8^{\circ}-1.2^{\circ} \mathrm{C}$ reported in the Special Report on Global Warming of $1.5^{\circ} \mathrm{C}$ produced by the Intergovernmental Panel on Climate Change (IPCC 2018). Adding $0.97^{\circ} \mathrm{C}$ to global mean warming of

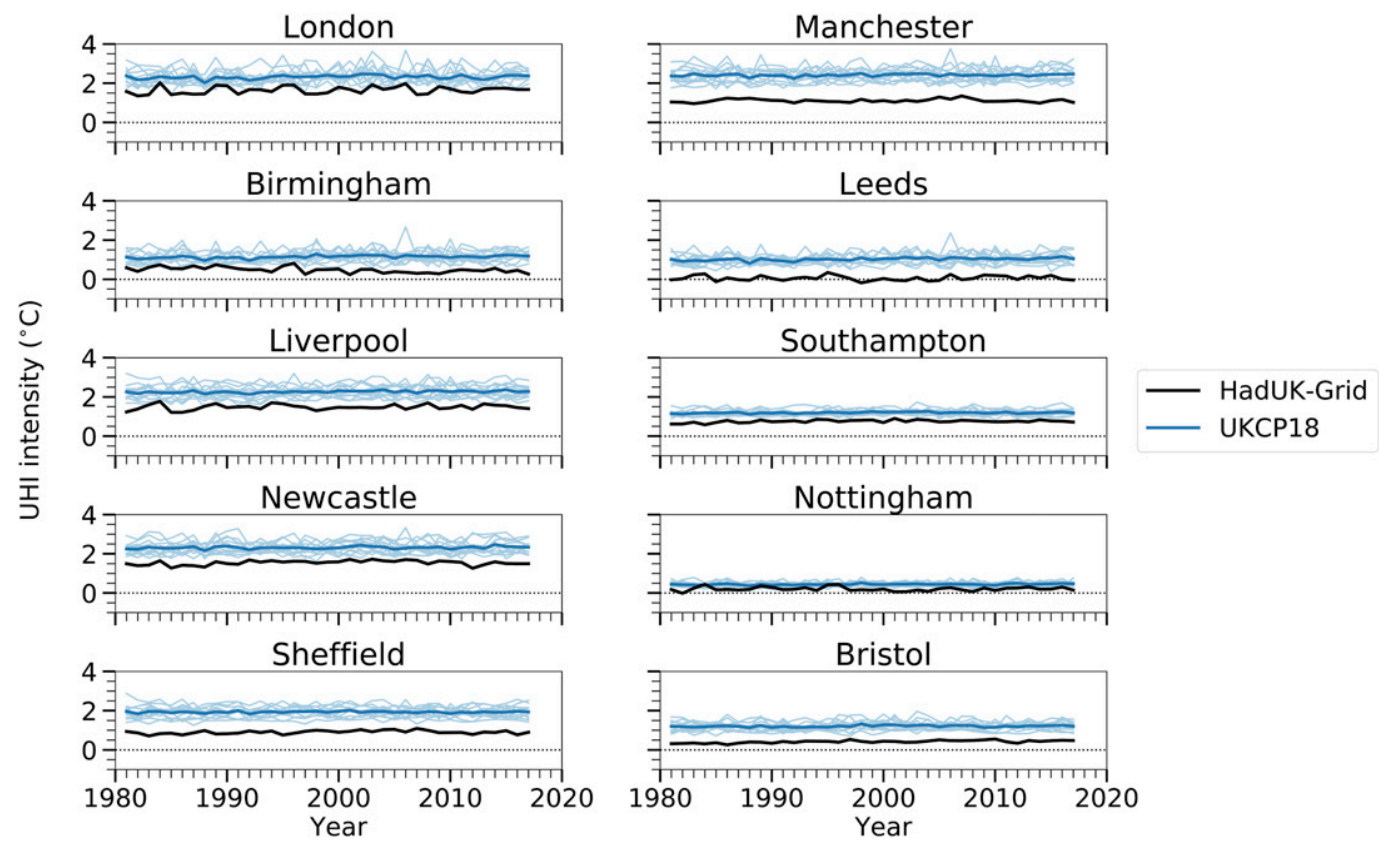

FIG. 4. As in Fig. 3, but for nighttime. 

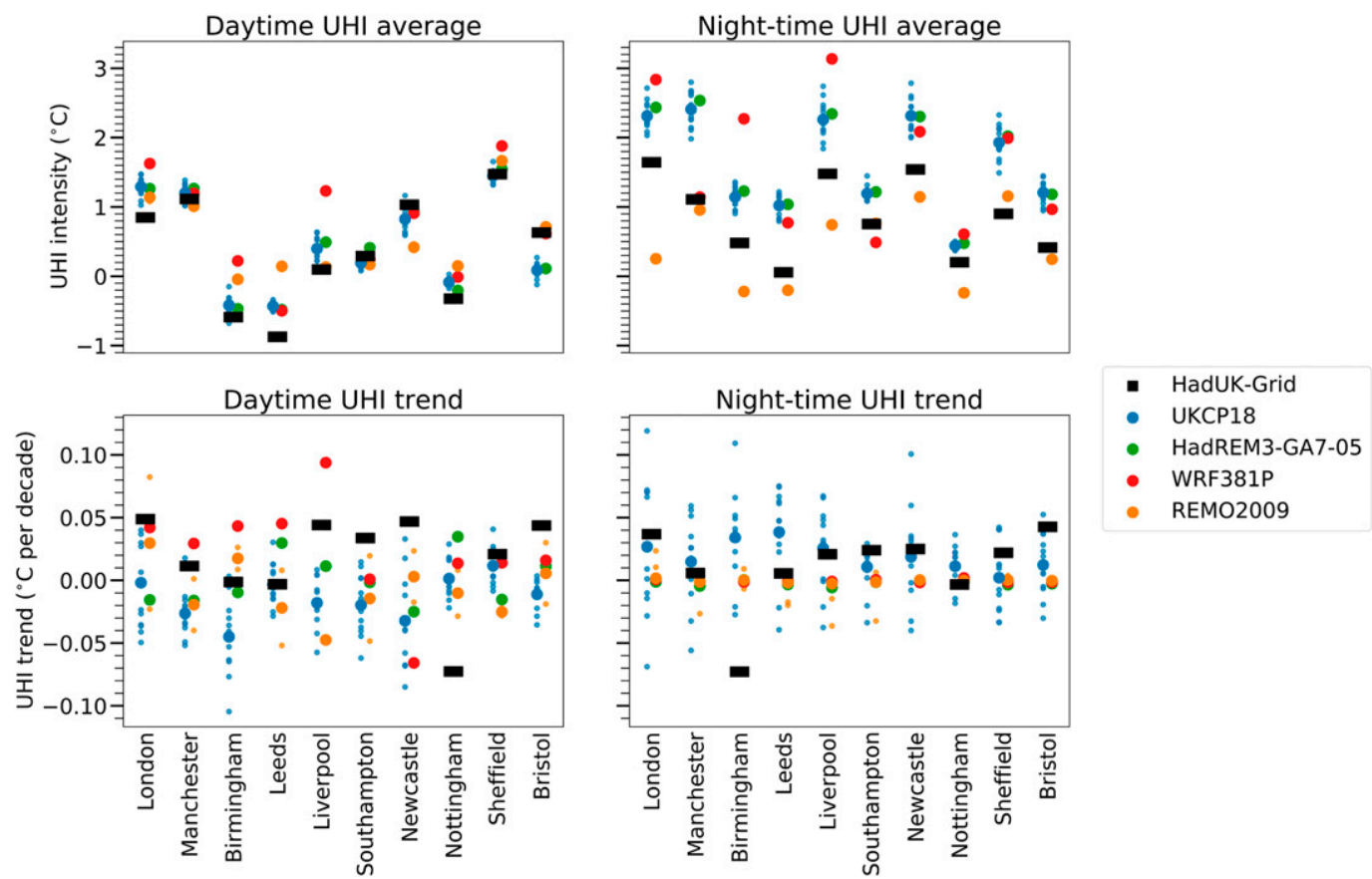

FIG. 5. Comparisons of 1981-2017 summer (JJA) (left) daytime and (right) nighttime UHI (top) intensities and (bottom) trends between HadUK-Grid (black rectangles), UKCP18-regional (blue dots), and three regional climate models in the EURO-CORDEX experiment (green dots for HadREM-GA7-05, red dots for WRF381P, and orange dots for REMO2009). Small dots indicate results from individual ensemble members, and big dots indicate the ensemble means.

emergence allows us to compare our emergence results with the temperature thresholds of $1.5^{\circ}, 2^{\circ}$, and $3^{\circ} \mathrm{C}$ above preindustrial levels in sections $3 \mathrm{c}$ and $3 \mathrm{~d}$.

\section{Results}

\section{a. Projected urban and rural temperature trends}

Figure 6 shows that both summer daytime and nighttime temperatures over both urban and rural areas in UKCP18-regional are projected to increase with time in all studied cities in the period 1981-2079. This is expected from the increasing radiative forcing in RCP8.5. UKCP18-regional simulates larger upward trends in daytime than nighttime temperature for both urban and rural areas.

Depending on the location, the warming rates of ensemblemean rural daytime temperature range from $0.62^{\circ}$ to $0.81^{\circ} \mathrm{C}$ per decade, whereas those of urban daytime temperature range from $0.57^{\circ}$ to $0.78^{\circ} \mathrm{C}$ per decade (red dots in Fig. 6). All these positive ensemble-mean daytime temperature trends are statistically significant at the 5\% level. For all cities except Sheffield, a unit increase in rural daytime temperature is associated with a smaller increase in urban daytime temperature. These differential warming rates mean that daytime UHI intensity is expected to decrease with time in all studied cities but Sheffield (Fig. 7 and top panel of Fig. 8). The trends in UHI intensity will be explored in detail in the following section.

On the contrary, for every unit increase in ensemble-mean rural nighttime temperature, there is a larger increase in urban nighttime temperature (blue dots in Fig. 6). This is true for all cities: the warming rates of rural nighttime temperature range from $0.45^{\circ}$ to $0.51^{\circ} \mathrm{C}$ per decade, whereas that of urban nighttime temperature range from $0.48^{\circ}$ to $0.55^{\circ} \mathrm{C}$ per decade. All these nighttime warming trends are also statistically significant at the $5 \%$ level. However, higher nighttime warming rates in urban areas than rural areas mean that ensemble-mean upward trends in nighttime UHI intensity are expected in all cities in the period 1981-2079 (Fig. 7 and top panel of Fig. 8).

\section{b. Projected UHI intensity trends}

Figure 7 shows the time evolution of summer daytime and nighttime UHI intensities in the cities between 1981 and 2079. These are UHI intensities calculated from bias-corrected UKCP18-regional temperatures (see section 2e). The thin lines indicate simulations from individual UKCP18-regional ensemble members, whereas the thick lines indicate the ensemble means. Some cities (e.g., Newcastle) show a larger ensemble spread in simulated UHI intensity than other cities (e.g., Sheffield). These differences are not related to the differences in city size, average UHI intensity, or warming level across the cities (not shown), and their causes will require research beyond this study.

For seven of the cities (excluding Manchester, Sheffield, and Bristol), UKCP18-regional simulates higher summer nighttime than daytime UHI intensity in all years. This is consistent with the diurnal cycle of urban/rural temperature contrast reported in the literature (see section 1). It is the result of larger urban 


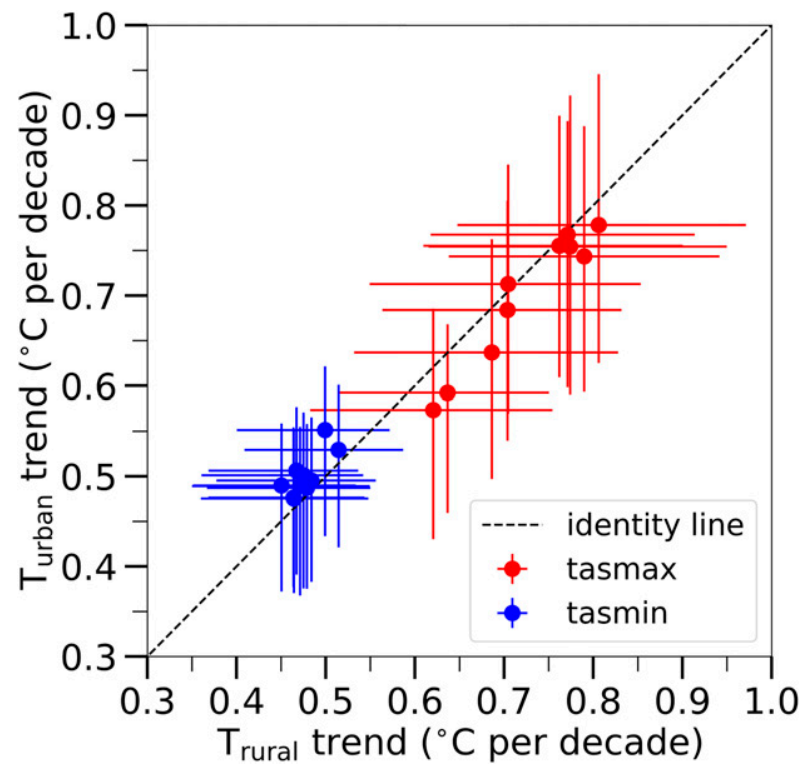

FIG. 6. Comparison of trends of urban and rural temperatures $\left({ }^{\circ} \mathrm{C}\right.$ per decade) over summers (JJA) in 1981-2079. Each dot represents one studied city. The error bars indicate the 12 -member ensemble spread of UKCP18-regional. Red dots and blue dots show trends in summer daily maximum and minimum temperature, respectively. The dashed line shows the identity line.

thermal inertia that maintains a positive sensible heat flux and higher urban than rural air temperature at night.

While ensemble-mean summer nighttime UHI intensities remain positive for all cities in almost all years, the ensemblemean daytime UHI intensities for Birmingham, Leeds, and Nottingham are consistently below $0^{\circ} \mathrm{C}$ during the 1981-2079 period (Fig. 7). The ensemble-mean daytime UHI intensity is projected to drop below $0^{\circ} \mathrm{C}$ in Liverpool and Southampton in the second half of the simulation period too. This means summer urban cool islands exist in these cities during the day and they will strengthen in the twenty-first century, according to the UKCP18-regional simulations. These summer daytime urban cool islands are likely to be the result of a phase delay in the increase in upward sensible heat flux in the urban areas during the day because of their large thermal inertia (Bohnenstengel et al. 2011). We discuss urban cool islands around the world in section 4.

By 2080, London's ensemble-mean summer nighttime UHI intensity is projected to increase to $2.1^{\circ} \mathrm{C}$, whereas its daytime $\mathrm{UHI}$ intensity is projected to decrease slightly to $0.8^{\circ} \mathrm{C}$ (Fig. 7). An increase in ensemble-mean summer nighttime UHI intensity is found for all cities, but at various rates (Fig. 8, top panel). The four largest cities (London, Manchester, Birmingham, and Leeds) show larger upward nighttime UHI intensity trends (at $0.03^{\circ}-0.05^{\circ} \mathrm{C}$ per decade) than the rest of the cities. This suggests that future changes in nighttime UHI intensity are related to the degree of urbanization, even though urban fractions do not evolve with time in the simulations. Note that individual ensemble members of UKCP18-regional (crosses in Fig. 8) do not agree on the sign of trend for Newcastle.
Conversely, the ensemble-mean summer daytime UHI intensity trends are downward in all cities except Sheffield (Fig. 8, top panel). Manchester, Liverpool, Birmingham, and Newcastle are projected to experience the largest mean downward trends at $-0.04^{\circ}$ to $-0.05^{\circ} \mathrm{C}$ per decade. These downward trends may be linked to projected reductions in summer soil moisture in the UKCP18 simulations in the twenty-first century (Murphy et al. 2018). As soil moisture reduces, cooling through evapotranspiration in rural areas becomes less effective, reducing the urban/rural contrast in near-surface air temperature during the day, when most evapotranspiration occurs. The UKCP18-regional ensemble members do not agree on the sign of daytime UHI intensity trend in London, Nottingham, and Sheffield, indicating less confidence in the overall trend for daytime than nighttime UHI intensity in England.

Considering the three consecutive warmest days each year instead of the whole summer season amplifies the 1981-2079 ensemble-mean upward nighttime UHI intensity trend and downward daytime UHI intensity trend in most cities (Fig. 8, bottom panel). The most pronounced example for nighttime UHI intensity trend amplification is Birmingham, which is projected to experience a $0.07^{\circ} \mathrm{C}$ per decade increase in nighttime UHI intensity on its annual warmest days, compared to a $0.04^{\circ} \mathrm{C}$ per decade increase over summers. For daytime UHI intensities, London would experience a $-0.08^{\circ} \mathrm{C}$ per decade decrease in urban temperatures relative to rural temperatures on its annual warmest days, compared to a $-0.004^{\circ} \mathrm{C}$ per decade decrease in daytime UHI intensity over summers. The sign of ensemble-mean trend changes from positive to negative for nighttime UHI intensity in Sheffield and Bristol, and for daytime UHI intensity in Sheffield. The ensemble spread is generally larger on annual warmest days than over summers due to increased variability, leading to more ensemble disagreements on the sign of trends.

\section{c. Emergence of temperature signals}

We examine whether the upward trends in summer daytime and nighttime temperatures over the studied urban and rural areas (Fig. 6) would emerge from climate variability in UKCP18-regional in this section. Figure 9 shows the global mean warming of emergence of summer urban (filled triangles) and rural (empty triangles), daytime (red) and nighttime (blue) temperature signals in and surrounding the cities. The right $y$ axis of Fig. 9 indicates the corresponding year of emergence based on the ensemble mean of UKCP18-global, expressed in the number of years after 2013 (the middle year of the reference period, 2008-18). Recall that year of emergence is defined as the middle year of the future 11-yr period during which the new temperature distribution is statistically significantly different from the reference (2008-18) distribution at the 5\% level (see section $2 \mathrm{f}$ ).

The distributions of summer urban and rural, daytime and nighttime temperatures would be statistically significantly (at the 5\% level) different from their respective 2008-18 distributions when the globe becomes $0.2^{\circ}-0.27^{\circ} \mathrm{C}$ warmer than the $2008-18$ period. This means the positive temperature signals would all emerge below $1.25^{\circ} \mathrm{C}$ global warming 

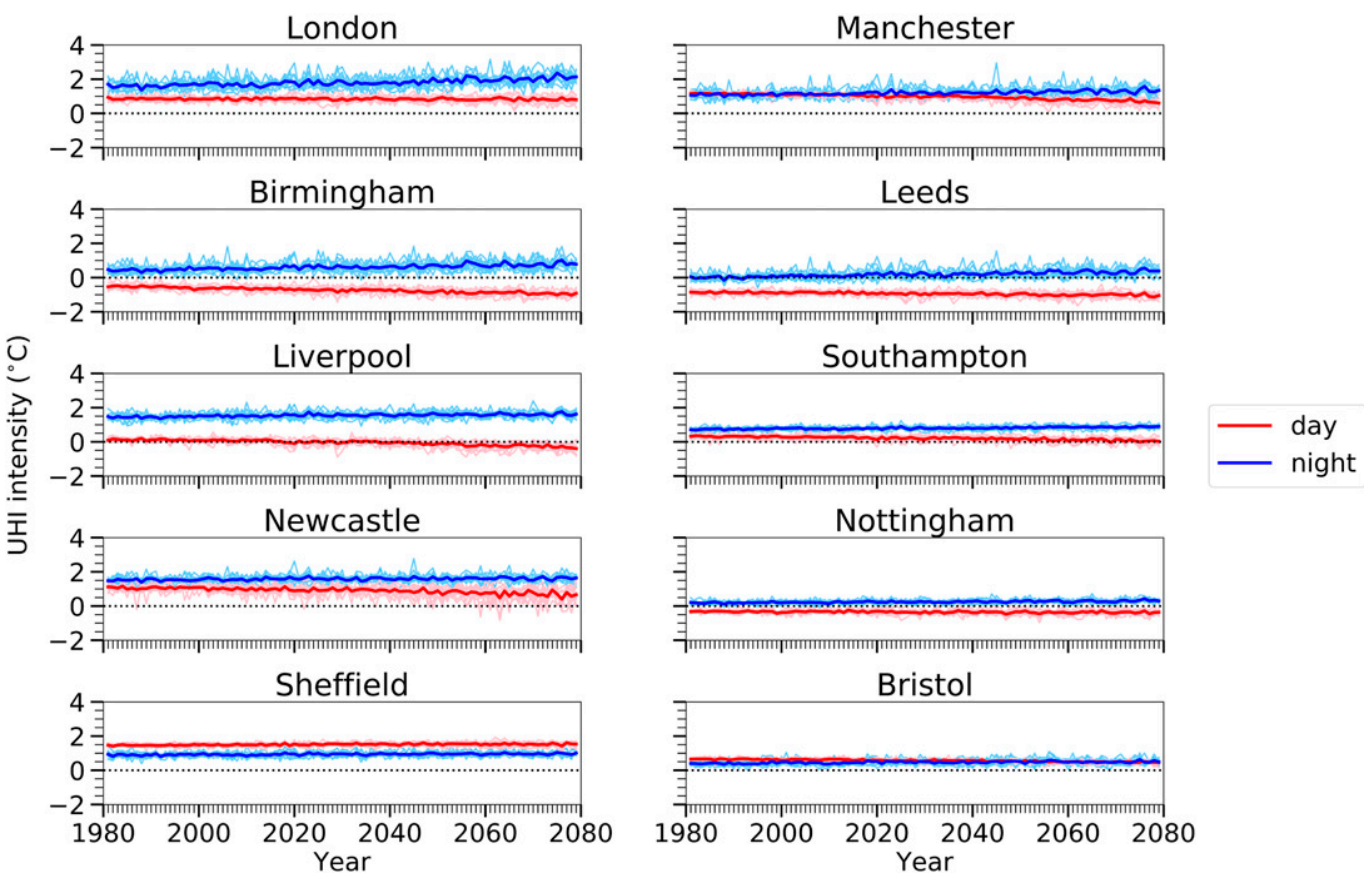

FIG. 7. Time evolution of bias-corrected summer (JJA) daytime (red) and nighttime (blue) UHI intensities from UKCP18-regional during 1981-2079. Thick lines indicate the ensemble means, and thin lines indicate individual ensemble members.

above preindustrial levels, below the $1.5^{\circ} \mathrm{C}$ Paris Agreement limit.

As shown by the right $y$ axis of Fig. 9; all summer urban and rural, daytime and nighttime temperature signals are expected to emerge from 2008-18 variability earlier than or about 6 years after 2013, if the model is correct. This means around year 2019, the middle year of the 2014-24 period, all these temperature signals would emerge in the UKCP18 simulations. At the time of writing (early 2020), this means there is a $\sim 50 \%$ chance that these positive daytime and nighttime temperature signals have already emerged from 2008-18 variability over the included urban and rural grid boxes. This also means that these warming signals are projected to emerge within half a decade if they have not already.

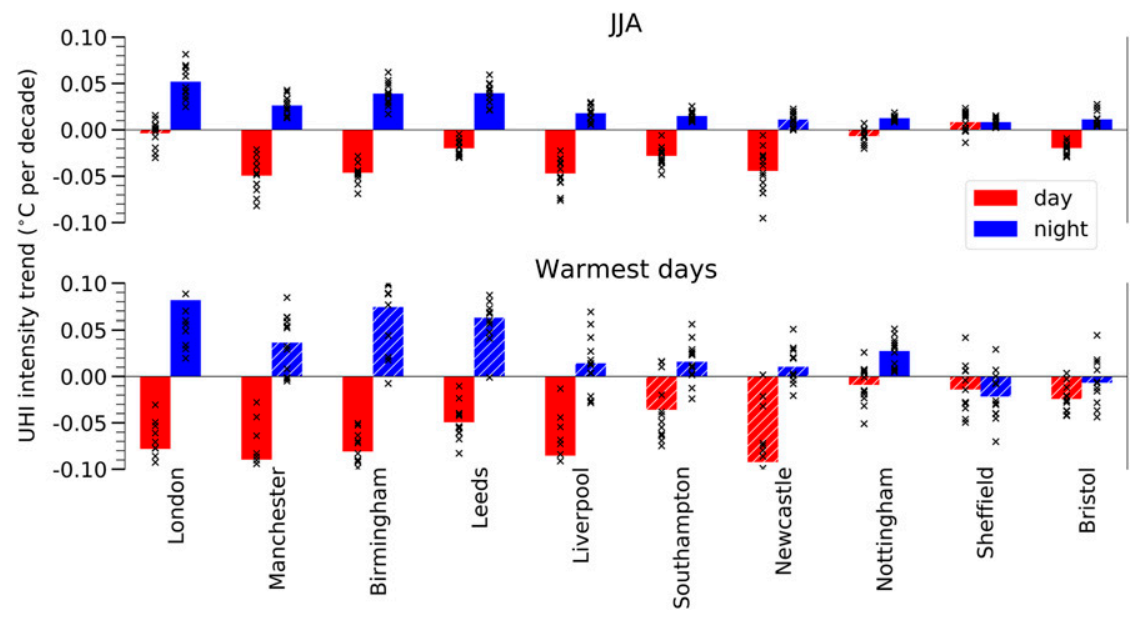

FIG. 8. UHI intensity trends $\left({ }^{\circ} \mathrm{C}\right.$ per decade) in 1981-2079 for daytime (red) and nighttime (blue) near-surface air temperatures. The bars show the UKCP18-regional ensemble-mean values, and the crosses indicate individual ensemble members. Bars for which the 12-member ensemble range crosses zero are hatched. Shown are trends in (top) summer (JJA) and (bottom) UHI intensities on annual three consecutive warmest days. 


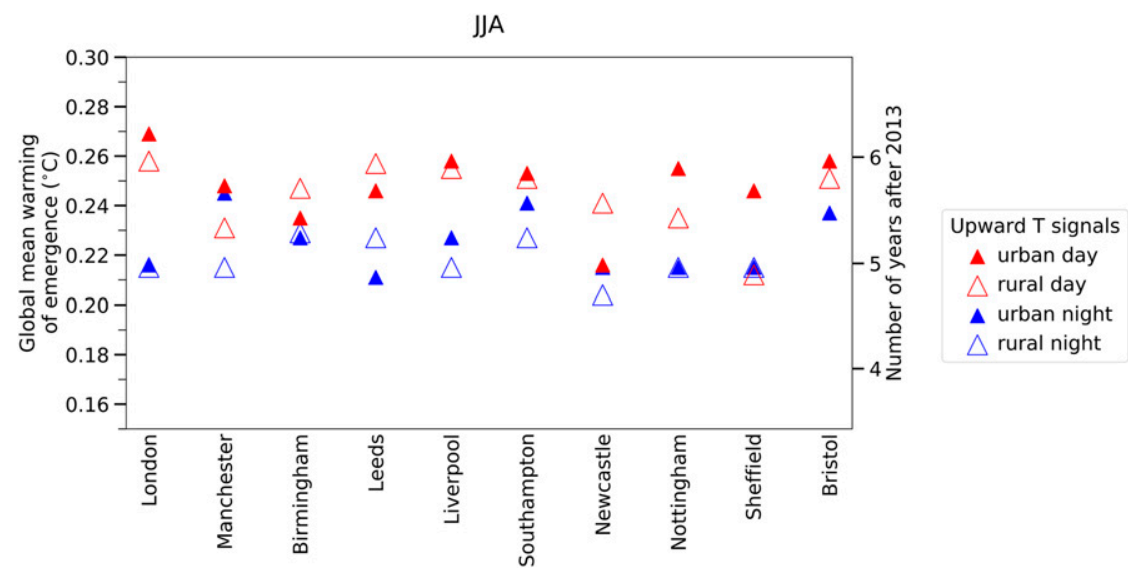

FIG. 9. Global mean warming of emergence of summer daytime (red) and nighttime (blue) urban (filled triangles) and rural (open triangles) temperature signals in and around the 10 most populous cities in England. All signals are positive as indicated by the upward triangles. Warming of emergence is measured in global mean warming in degrees Celsius since 2008-18. The right vertical axis shows the corresponding number of years after 2013 (the middle year of the 2008-18 baseline), based on the ensemble mean of the UKCP18-global simulations. Here, $1.5^{\circ} \mathrm{C}$ of global warming above preindustrial levels corresponds to $0.53^{\circ} \mathrm{C}$ warming since the average of $2008-18$, which is above the vertical scale of this figure.

\section{d. Emergence of UHI signals}

We now investigate whether the differential trends in summer daytime and nighttime UHI intensity would also emerge from 2008-18 variability in the UKCP18 simulations. Figure 10 shows the global mean warming of emergence of summer daytime and nighttime UHI signals in the cities, with indicators of the $1.5^{\circ}$ and $2^{\circ} \mathrm{C}$ Paris Agreement targets, and the $3^{\circ} \mathrm{C}$ global warming above preindustrial levels implied by current NDCs. It also shows the corresponding year of emergence for completion.

In all cities except Newcastle, the upward trend in summer nighttime UHI intensity (upward blue triangles in Fig. 10) would emerge from 2008-18 variability when global mean warming goes above $0.8^{\circ} \mathrm{C}$ above the most recent (2008-18) levels. At $0.8^{\circ}-0.9^{\circ} \mathrm{C}$ above the most recent levels, summer nighttime UHI intensities in Birmingham and Leeds would become statistically significantly higher (at the $5 \%$ level) than their reference values. Five other cities (Bristol, Southampton, London, Manchester, and Liverpool) would have their summer nighttime UHI intensity signals emerge from variability $\sim 1^{\circ}$ $2^{\circ} \mathrm{C}$ above the $2008-18$ levels (i.e., $2^{\circ}-3^{\circ} \mathrm{C}$ above preindustrial levels). In Nottingham and Sheffield, the positive summer nighttime UHI intensity signal would emerge at $2.9^{\circ}$ and $3.2^{\circ} \mathrm{C}$ global warming above the $2008-18$ levels (i.e., $\sim 4^{\circ} \mathrm{C}$ above preindustrial levels).

At their respective global mean warming of emergences, the magnitudes of summer nighttime UHI intensity in the cities (except Newcastle) are projected to be (in ascending order of emergence) $0.6^{\circ} \mathrm{C}$ in Birmingham, $0.1^{\circ} \mathrm{C}$ in Leeds, $0.4^{\circ} \mathrm{C}$ in Bristol, $0.8^{\circ} \mathrm{C}$ in Southampton, $1.8^{\circ} \mathrm{C}$ in London, $1.4^{\circ} \mathrm{C}$ in Manchester, $1.5^{\circ} \mathrm{C}$ in Liverpool, $0.3^{\circ} \mathrm{C}$ in Nottingham, and $1^{\circ} \mathrm{C}$ in Sheffield.
Nine of the cities (excluding Sheffield) would have their summer daytime UHI intensity reductions emerge from 200818 variability in the UKCP18-regional simulations (downward red triangles in Fig. 10 indicate negative daytime UHI signals). In many of these places (except London and Nottingham), the daytime emergences happen at lower global warming levels than the corresponding nighttime emergences. The global mean warming of emergences of the daytime UHI intensity signal in Manchester, Liverpool, Birmingham, Bristol, and Southampton range between $0.2^{\circ}$ and $0.5^{\circ} \mathrm{C}$ above the 2008-18 levels. These are equivalent to warmings below $1.5^{\circ} \mathrm{C}$ above preindustrial levels (i.e., the stricter Paris Agreement target). By $2^{\circ}$ and $3^{\circ} \mathrm{C}$ global warming above preindustrial levels; the downward trend in summer daytime UHI intensity in Leeds and Newcastle would also emerge.

At their respective global mean warming of emergences, the magnitudes of summer daytime UHI intensity in the cities (except Sheffield) are projected to be (in ascending order of emergence) $1{ }^{\circ} \mathrm{C}$ in Manchester, $-0.05^{\circ} \mathrm{C}$ in Liverpool, $-0.7^{\circ} \mathrm{C}$ in Birmingham, $0.6^{\circ} \mathrm{C}$ in Bristol, $0.3^{\circ} \mathrm{C}$ in Southampton, $-0.9^{\circ} \mathrm{C}$ in Leeds, $0.9^{\circ} \mathrm{C}$ in Newcastle, $-0.4^{\circ} \mathrm{C}$ in Nottingham, and $0.9^{\circ} \mathrm{C}$ in London. More than half of these cities would still be warmer than their rural surroundings during the day despite the projected emergent, downward trends in daytime UHI intensity.

With few exceptions, we find higher global mean warming of emergences of daytime and nighttime UHI intensity signals on annual warmest days than in summer (not shown), even though most of the trends are amplified on annual warmest days. We attribute this to increased intra-ensemble and interannual UHI intensity variabilities when considering only the three consecutive warmest days each year. Nevertheless, the emergent yet opposite trends in daytime and nighttime UHI intensity found 


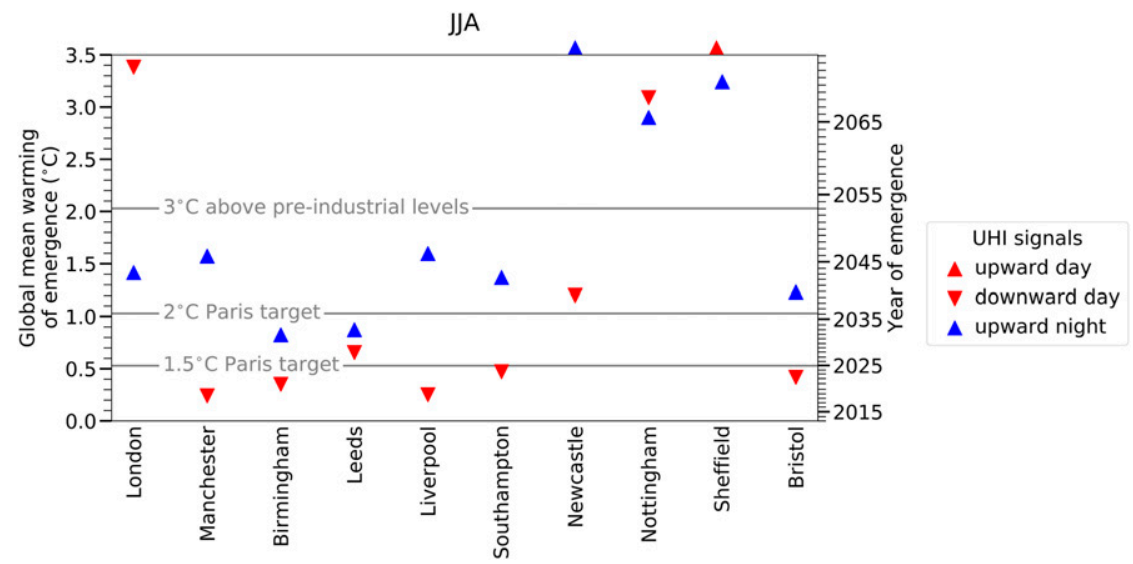

FIG. 10. Global mean warming of emergence of summer daytime (red) and nighttime (blue) UHI signals in the 10 most populous cities in England. Upward triangles indicate positive (upward) signals, whereas downward triangles indicate negative (downward) signals. Warming of emergence is measured in global mean warming in degrees Celsius since 2008-18. The right vertical axis shows the corresponding year of emergence based on the ensemble mean of the UKCP18-global simulations. The gray horizontal lines indicate the Paris Agreement temperature targets and $3^{\circ} \mathrm{C}$ global warming above preindustrial levels (1850-1900), based on the UKCP18-global simulations and global mean warming between 1850-1900 and 2008-18 in HadCRUT4-CW. Triangles on top of the figure indicate daytime (red) and nighttime (blue) UHI changes that do not emerge in the UKCP18 simulations.

in this study provide a scientific basis for future urban planning in England.

\section{Discussion}

Assuming constant urbanization in UKCP18-regional, we have found upward trends in bias-corrected, summer daytime and nighttime temperatures over both urban and rural grid boxes in the 10 most populous built-up areas in England over the period 1981-2079. Despite their varying warming rates (Fig. 6), all these temperature signals are projected to emerge from $2008-18$ variability below $1.25^{\circ} \mathrm{C}$ global mean warming above preindustrial (1850-1900) levels. According to UKCP18global, these emergences are expected to occur in 11-yr periods centered on or before year 2019, suggesting that they may have already occurred (Fig. 9).

Using a different reference period (1860-1910) and 23 climate model simulations, King et al. (2015) found the median time of emergence of summer highest maximum temperature to be between 2000 and 2020 over the United Kingdom, but that of summer lowest minimum temperature to be between 1980 and 2020. We are unable to compare our results with King et al.'s (2015) like-for-like because of a lack of pre-1980 UKCP18-regional data. Nevertheless, both our studies suggest that emergence of warming signals may have already occurred in at least part of the United Kingdom. This has important implications for public health in the United Kingdom, because elevated summer temperatures are known to increase heat stress, inhibit recovery from heat loads, and disrupt sleep (Libert et al. 1988; Fischer and Schär 2010; Grize et al. 2005).

UKCP18-regional projects, on average, a $0.05^{\circ} \mathrm{C}$ per decade increase in summer nighttime UHI intensity in London, from $\sim 1.6^{\circ} \mathrm{C}$ in the 1980 s to $2.1^{\circ} \mathrm{C}$ by 2080 (Figs. 7 and 8). Our $1980 \mathrm{~s}$ value is lower than the observed $\sim 2^{\circ} \mathrm{C}$, which was estimated by Wilby (2003) through comparing 1961-90 summer temperatures between an urban and a rural weather station in London. This suggests that our UHI estimates are conservative as a result of our two-grid approach to identifying urban and rural areas (section $2 \mathrm{~d}$ ). However, our approach provides a new way for systematically estimating UHI intensities across the United Kingdom from gridded datasets, rather than individual weather stations that are prone to errors and uncertainty.

Using climate and statistical models, Wilby (2003) projected a $0.3^{\circ} \mathrm{C}$ increase in London's summer nighttime UHI intensity between 1961-90 and the 2080s, whereas Wilby (2008) projected a strengthening of summer nighttime UHI intensity to $\sim 3^{\circ} \mathrm{C}$ in London by the 2050 s. By coupling an RCM to an urban surface scheme, however, McCarthy et al. (2012) simulated an unaltered summer nighttime UHI for London between 1971-90 and 2041-60. Our results are qualitatively consistent with the former two studies, given that a different future climate change scenario (RCP8.5) is used here.

In the daytime, we have found that summer urban cool islands exist and will strengthen with time in five included cities (Fig. 7). Summer daytime urban cool islands have been observed in various parts of the world (Yang et al. 2017), including in midlatitude European cities (Acero et al. 2013; Gonçalves et al. 2018), albeit less frequently than urban heat islands. In addition to a daytime sensible heat flux phase delay (section 3b); urban cool islands around the world have been attributed to air pollution attenuating solar radiation (Memon et al. 2009), little anthropogenic heat from cars and homes (Yang et al. 2017), cool urban green spaces as a result of evapotranspiration and shading by trees (Gonçalves et al. 
2018), sea breeze cooling of coastal cities (Suomi and Käyhkö 2012; Acero et al. 2013), differences between early morning urban and rural mixed layer depths (Theeuwes et al. 2015), and tall buildings shading the street level (Oke 1987; Erell and Williamson 2007). However, tall buildings are not captured in UKCP18-regional's one-tile urban scheme (see section 2b).

McCarthy et al. (2012) simulated a $0.1^{\circ} \mathrm{C}$ decrease in summer daytime UHI intensity for London between 1971-90 and 204160. The UKCP18-regional ensemble mean also simulates a decrease in London's summer daytime UHI intensity over time, although individual ensemble members disagree on the sign of change (Fig. 8). Previous studies on UHI projection in the United Kingdom mainly focused on the nighttime intensity in London, making comparison of the rest of our projections with the literature impossible. By filling this gap in the literature, our study provides the basis for future comparisons when more research on daytime UHI intensity changes in smaller U.K. cities becomes available.

For other parts of the world, various changes in UHI intensity have been projected in previous studies, depending on the region, season and climate change scenario (Oleson et al. 2011; Oleson 2012; Argüeso et al. 2014; Lauwaet et al. 2015; Chapman et al. 2017). In Europe, a decrease in summer daytime UHI intensity (Hamdi et al. 2014, 2015) and an unaltered or a decrease in summer nighttime UHI intensity (Hamdi et al. 2014; Lauwaet et al. 2016) were projected for Brussels; a decrease in both summer daytime (Hamdi et al. 2015) and nighttime UHI intensities (Lemonsu et al. 2013) was projected for Paris, whereas an increase in average summer UHI intensity was projected for Berlin (Grossman-Clarke et al. 2017). Note, however, that UHIs can also occur in winter; although they are generally less pronounced than summer UHIs in the United Kingdom and other midlatitude cities (Kershaw et al. 2010). This is because absorption of solar radiation by buildings dominates the formation of UHIs in summer in these cities (Kershaw et al. 2010). For Arctic climates, more pronounced winter UHI increases were observed than summer UHI increases (e.g., Magee et al. 1999), but this is beyond the scope of this study.

As evidenced by the examples for London and Brussels above, contrasting UHI projections can be found for the same UHI metric and season in the literature as a result of different modeling methods. Our focus in this study has been on the new UKCP18-regional dataset because it is the gold standard for U.K. climate simulations. It was specifically designed for research like this, with enough ensemble members to show confidence in the results. Figure 11 shows that selected EUROCORDEX models (see section 2c) simulate a range of summer UHI intensity responses in the included cities under RCP8.5. For daytime UHI, WRF381P and REMO2009 simulate smaller, and in some cases opposite, trends than UKCP18-regional and HadREM3-GA7-05 (EURO-CORDEX version). For nighttime UHI, there is little agreement between EURO-CORDEX and UKCP18-regional. Therefore, the main results of this study-a projected decrease in summer daytime and a projected increase in summer nighttime UHI intensity in major English cities-are specific to the UKCP18-regional configuration, which we believe is best suited for this analysis.
Based on UKCP18-regional, the downward summer daytime UHI intensity signals in UKCP18-regional would emerge from 2008-18 variability in five included cities before global mean temperature reaches $1.5^{\circ} \mathrm{C}$ above preindustrial levels (Fig. 10). We stress that this does not mean climate change will be beneficial to increasing thermal comfort in urban areas, because both urban and rural temperatures are expected to rise significantly in the twenty-first century (Fig. 6). A reduction in daytime UHI intensity is simply the outcome of different rates of warming between urban and rural areas.

Conversely, the upward nighttime UHI intensity signals would emerge in seven cities below $3^{\circ} \mathrm{C}$ global mean warming above preindustrial levels, further strengthening the contrasts between rising urban and rural temperatures around these cities. These emergent changes might alter mesoscale atmospheric circulations and in turn the spatial and diurnal distributions of air pollutants (see section 1), although research is needed to test this hypothesis.

This study has made use of the newest generation of UKCP to estimate future changes in, and potential emergences of, summer temperatures and UHI intensities in England. While UKCP18-regional is state-of-the-art in many ways (Murphy et al. 2018), this urban heat study comes with a few limitations. As shown above, our main results are specific to the UKCP18regional configuration. Having focused on UKCP18-regional rather than EURO-CORDEX, the latter of which was not solely designed for U.K. climate projections, we have not investigated the reasons behind the differences in UHI intensity trends between the climate models.

Second, UKCP18-regional does not include time-varying urban land use (see section $2 \mathrm{~b}$ ). Our urban temperature and UHI emergence estimates are therefore based on present-day urbanization and projected climate warming. Third, the $12-\mathrm{km}$ resolution of UKCP18-regional is just fine enough to resolve the Bristol BUA (Table 1). This may have led to an underestimation of UHI intensities in the smaller cities.

Moreover, subdaily air temperature, cloud cover, and wind outputs are not available from UKCP18-regional at the time of writing. By using the urban/rural differences in daily maximum and minimum temperatures as proxies for daytime and nighttime UHI intensities, we have not accounted for the fact that daily maximum and minimum temperatures often occur at different times in urban and rural areas due to a phase shift in the surface energy balance (see section 1). Without subdaily cloud cover and wind data, or any soil moisture data at the global or regional scale, we have only been able to qualitatively discuss the potential reasons for decreasing summer daytime UHI intensities and the potential impacts of future UHI intensity changes on air pollutant concentrations.

Future research is recommended to investigate the drivers of the differences in UHI intensity trends between UKCP18regional and EURO-CORDEX simulations. To understand how future urbanization and climate change will affect urban and rural temperatures and the UHI effect, future work could expand this work by incorporating land use as well as climate projections. Earlier this year the Met Office released UKCP18-local, a set of 2.2-km projections that resolve small-scale 

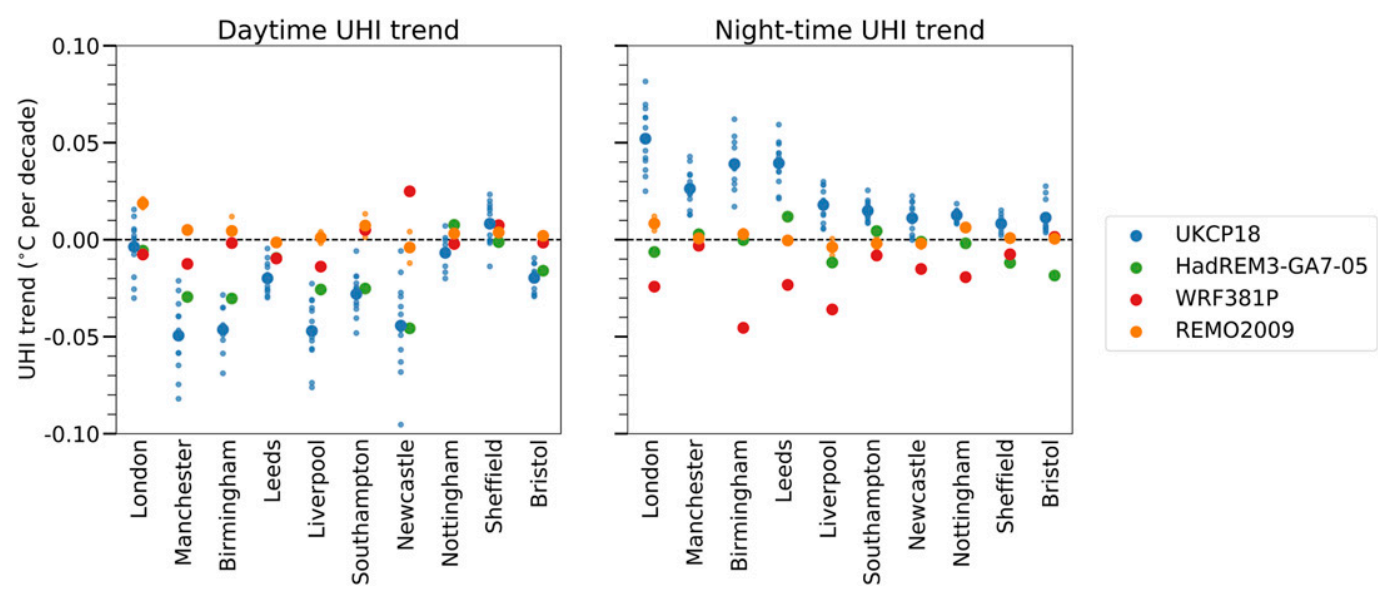

FIG. 11. Comparisons of 1981-2079 summer (JJA) (left) daytime and (right) nighttime UHI intensity trends between UKCP18-regional (blue dots) and three regional climate models in the EURO-CORDEX experiment (green dots for HadREM-GA7-05, red dots for WRF381P, and orange dots for REMO2009). Small dots indicate results from individual ensemble members, and big dots indicate the ensemble means.

phenomena including atmospheric convection (Kendon et al. 2019). The convection-permitting model uses a two-tile urban scheme that represents roofs and street canyon facets (Porson et al. 2010), instead of the one-tile scheme used in UKCP18regional (section 2 b). Subdaily climate variable outputs are also becoming available for time slices spanning 1981-2000, 2021-40, and 2061-80 as this paper is being written (Kendon et al. 2019). This subdaily dataset will be very useful for understanding the processes that drive the differential changes between daytime and nighttime UHIs found in this study. Using UKCP18-local to further explore potential changes in the UHI effect, the drivers of these changes, and their impacts should be a priority of future work.

\section{Conclusions}

Rising urban and rural temperatures could increase human heat stress. Changes in UHI intensities could alter local atmospheric circulations and, in turn, distributions of air pollutants. Using UKCP18-regional, the 12-km simulations from the newest generation of the U.K. climate projections, we quantify trends in summer daytime and nighttime temperatures in urban and rural areas, as well as the UHI intensities in the 10 most populous builtup areas in England in the period 1981-2079. We find an increasing trend in both urban and rural daytime and nighttime temperatures in the RCP8.5 scenario. There is an $\sim 50 \%$ chance that positive temperature signals from all 10 cities have already emerged from 2008-18 variability.

Projected differential warming rates between summer urban and rural temperatures mean that summer daytime UHI intensity would decrease at rates from $-0.004^{\circ}$ to $-0.05^{\circ} \mathrm{C}$ per decade in nine of the cities, whereas summer nighttime UHI intensity would increase by $0.01^{\circ}-0.05^{\circ} \mathrm{C}$ per decade in all cities. The negative daytime UHI signals would emerge in Manchester, Liverpool, Birmingham, Bristol, and Southampton before global mean warming reaches $1.5^{\circ} \mathrm{C}$ above preindustrial levels, and in Leeds between $1.5^{\circ}$ and $2^{\circ} \mathrm{C}$ global warming.
Conversely, the increasing nighttime UHI signals would emerge from 2008-18 variability in Birmingham and Leeds when global mean warming is between $1.5^{\circ}$ and $2^{\circ} \mathrm{C}$ above preindustrial levels. These results provide important information for future municipal adaptation and urban planning in the United Kingdom, in the context of internationally recognized temperature thresholds. Since our emergence results are based on present-day urbanization and projected climate warming in UKCP18-regional, increasing urbanization would exacerbate the projected changes in urban temperatures and UHI intensities, potentially leading to earlier emergence.

Acknowledgments. We thank the UKCP18 team at the Met Office for making the data available. Data used in this paper are licensed under the Open Government Licence v3.0. We thank Lizzie Kendon and Simon Tucker for providing the land surface data of UKCP18. HadUK-Grid data can be accessed online (http://catalogue.ceda.ac.uk/uuid/4dc8450d889a491ebb 20e724debe2dfb), UKCP18-regional data on a 12-km grid over the United Kingdom are also available online (https://cata logue.ceda.ac.uk/uuid/589211abeb844070a95d061c8cc7f604), as are EURO-CORDEX data (https://www.euro-cordex.net/ 060378/index.php.en). Authors Y. T. E. Lo, D. M. Mitchell, M. Collins, G. C. Hegerl, and M. Joshi were funded under the NERC project EMERGENCE (NE/S005242/1). Lo was also funded by the NERC project HAPPI-Health (NE/R009554/1). Mitchell was also funded by a NERC fellowship (NE/N014057/1). Author S. Bohnenstengel was funded under the UK-China Research \& Innovation Partnership Fund through the Met Office Climate Science for Service Partnership (CSSP) China as part of the Newton Fund. Author E. Hawkins was supported by the National Centre for Atmospheric Science and the NERC REAL Projections project (NE/N018486/1). Author P. A. Stott was supported by the Met Office Hadley Centre Climate Programme funded by BEIS and Defra. The authors declare that they have no conflict of interest. 


\section{REFERENCES}

Acero, J. A., J. Arrizabalaga, S. Kupski, and L. Katzschner, 2013: Urban heat island in a coastal urban area in northern Spain. Theor. Appl. Climatol., 113, 137-154, https://doi.org/10.1007/ s00704-012-0774-z.

Agarwal, M., and A. Tandon, 2010: Modeling of the urban heat island in the form of mesoscale wind and of its effect on air pollution dispersal. Appl. Math. Modell., 34, 2520-2530, https://doi.org/10.1016/j.apm.2009.11.016.

Allen, L., F. Lindberg, and C. S. B. Grimmond, 2011: Global to city scale urban anthropogenic heat flux: Model and variability. Int. J. Climatol., 31, 1990-2005, https://doi.org/10.1002/joc.2210.

Argüeso, D., J. P. Evans, L. Fita, and K. J. Bormann, 2014: Temperature response to future urbanization and climate change. Climate Dyn., 42, 2183-2199, https://doi.org/10.1007/ s00382-013-1789-6.

Basara, J. B., H. G. Basara, B. G. Illston, and K. C. Crawford, 2010: The impact of the urban heat island during an intense heat wave in Oklahoma City. Adv. Meteor., 2010, 1-10, https:// doi.org/10.1155/2010/230365.

Best, M. J., 2005: Representing urban areas within operational numerical weather prediction models. Bound.-Layer Meteor., 114, 91-109, https://doi.org/10.1007/s10546-004-4834-5.

_ , and Coauthors, 2011: The Joint UK Land Environment Simulator (JULES), model description-Part 1: Energy and water fluxes. Geosci. Model Dev., 4, 677-699, https://doi.org/ 10.5194/gmd-4-677-2011.

Bodas-Salcedo, A., J. P. Mulcahy, T. Andrews, K. D. Williams, M. A. Ringer, P. R. Field, and G. S. Elsaesser, 2019: Strong dependence of atmospheric feedbacks on mixed-phase microphysics and aerosol-cloud interactions in HadGEM3. J. Adv. Model. Earth Syst., 11, 1735-1758, https://doi.org/ 10.1029/2019MS001688.

Bohnenstengel, S. I., S. Evans, P. A. Clark, and S. E. Belcher, 2011: Simulations of the London urban heat island. Quart. J. Roy. Meteor. Soc., 137, 1625-1640, https://doi.org/10.1002/qj.855.

_ I. Hamilton, M. Davies, and S. E. Belcher, 2014: Impact of anthropogenic heat emissions on London's temperatures. Quart. J. Roy. Meteor. Soc., 140, 687-698, https://doi.org/ 10.1002/qj.2144.

Chapman, S., J. E. Watson, A. Salazar, M. Thatcher, and C. A. McAlpine, 2017: The impact of urbanization and climate change on urban temperatures: A systematic review. Landsc. Ecol., 32, 1921-1935, https://doi.org/10.1007/s10980-0170561-4.

Cowtan, K., and R. G. Way, 2014: Coverage bias in the HadCRUT4 temperature series and its impact on recent temperature trends. Quart. J. Roy. Meteor. Soc., 140, 1935-1944, https://doi.org/ 10.1002/qj.2297.

Cui, Y. Y., and B. De Foy, 2012: Seasonal variations of the urban heat island at the surface and the near-surface and reductions due to urban vegetation in Mexico City. J. Appl. Meteor. Climatol., 51, 855-868, https://doi.org/10.1175/JAMC-D-110104.1.

Dufresne, J. L., and Coauthors, 2013: Climate change projections using the IPSL-CM5 Earth system model: From CMIP3 to CMIP5. Climate Dyn., 40, 2123-2165, https://doi.org/10.1007/ s00382-012-1636-1.

Erell, E., and T. Williamson, 2007: Intra-urban differences in canopy layer air temperature at a mid-latitude city. Int. J. Climatol., 27, 1243-1255, https://doi.org/10.1002/joc.1469.

Fallmann, J., R. Forkel, and S. Emeis, 2016: Secondary effects of urban heat island mitigation measures on air quality. Atmos.
Environ., 125, 199-211, https://doi.org/10.1016/j.atmosenv.2015. 10.094.

Fenner, D., A. Holtmann, F. Meier, I. Langer, and D. Scherer, 2019: Contrasting changes of urban heat island intensity during hot weather episodes. Environ. Res. Lett., 14, 124013, https://doi.org/10.1088/1748-9326/ab506b.

Fischer, E. M., and C. Schär, 2010: Consistent geographical patterns of changes in high-impact European heatwaves. Nat. Geosci., 3, 398-403, https://doi.org/10.1038/ngeo866.

- K. W. Oleson, and D. M. Lawrence, 2012: Contrasting urban and rural heat stress responses to climate change. Geophys. Res. Lett., 39, L03705, https://doi.org/10.1029/2011GL050576.

Giorgetta, M. A., and Coauthors, 2013: Climate and carbon cycle changes from 1850 to 2100 in MPI-ESM simulations for the Coupled Model Intercomparison Project phase 5. J. $A d v$. Model. Earth Syst., 5, 572-597, https://doi.org/10.1002/jame. 20038.

Gonçalves, A., G. Ornellas, A. C. Ribeiro, F. Maia, A. Rocha, and M. Feliciano, 2018: Urban cold and heat island in the city of Bragança (Portugal). Climate, 6 (3), 1-14.

Grize, L., A. Huss, O. Thommen, C. Schindler, and C. BraunFahrländer, 2005: Heat wave 2003 and mortality in Switzerland. Swiss Med. Wkly., 135, 200-205.

Grossman-Clarke, S., S. Schubert, and D. Fenner, 2017: Urban effects on summertime air temperature in Germany under climate change. Int. J. Climatol., 37, 905-917, https://doi.org/ $10.1002 /$ joc. 4748 .

Hamdi, R., H. Van de Vyver, R. De Troch, and P. Termonia, 2014: Assessment of three dynamical urban climate downscaling methods: Brussels's future urban heat island under an A1B emission scenario. Int. J. Climatol., 34, 978-999, https:// doi.org/10.1002/joc.3734.

- O. Giot, R. De Troch, A. Deckmyn, and P. Termonia, 2015: Future climate of Brussels and Paris for the 2050s under the A1B scenario. Urban Climate, 12, 160-182, https://doi.org/ 10.1016/j.uclim.2015.03.003.

Heaviside, C., X. M. Cai, and S. Vardoulakis, 2015: The effects of horizontal advection on the urban heat island in Birmingham and the West Midlands, United Kingdom during a heatwave. Quart. J. Roy. Meteor. Soc., 141, 1429-1441, https://doi.org/ 10.1002/qj.2452.

_ S. Vardoulakis, and X.-M. Cai, 2016: Attribution of mortality to the urban heat island during heatwaves in the West Midlands, UK. Environ. Health, 15, S27, https://doi.org/ 10.1186/s12940-016-0100-9.

Hollis, D., M. McCarthy, M. Kendon, T. Legg, and I. Simpson, 2019: HadUK-Grid-A new UK dataset of gridded climate observations. Geosci. Data J., 6, 151-159, https://doi.org/ 10.1002/gdj3.78.

IPCC, 2018: Summary for policymakers. Global Warming of $1.5^{\circ} \mathrm{C}$ : An IPCC Special Report, V. Masson-Delmotte et al., Eds., World Meteorological Organization, 1-33, https://www.ipcc.ch/ sr15/chapter/spm/.

Jacob, D., and Coauthors, 2012: Assessing the transferability of the regional climate model REMO to different Coordinated Regional Climate Downscaling Experiment (CORDEX) regions. Atmosphere, 3, 181199, https://doi.org/10.3390/atmos3010181.

— , and Coauthors, 2014: EURO-CORDEX: New high-resolution climate change projections for European impact research. Reg. Environ. Change, 14, 563-578, https://doi.org/10.1007/s10113-013-0499-2.

Jones, C. D., and Coauthors, 2011: The HadGEM2-ES implementation of CMIP5 centennial simulations. Geosci. Model Dev., 4, 543-570, https://doi.org/10.5194/gmd-4-543-2011. 
Kendon, E., and Coauthors, 2019: UKCP convection-permitting model projections: Science report. Met Office Tech. Rep., 153 pp.

Kershaw, T., M. Sanderson, D. Coley, and M. Eames, 2010: Estimation of the urban heat island for UK climate change projections. Build. Serv. Eng. Res. Tech., 31, 251-263, https:// doi.org/10.1177/0143624410365033.

King, A. D., and Coauthors, 2015: The timing of anthropogenic emergence in simulated climate extremes. Environ. Res. Lett., 10, 094015, https://doi.org/10.1088/1748-9326/10/9/094015.

Lauwaet, D., H. Hooyberghs, B. Maiheu, W. Lefebvre, G. Driesen, S. Van Looy, and K. De Ridder, 2015: Detailed urban heat island projections for cities worldwide: Dynamical downscaling CMIP5 global climate models. Climate, 3, 391-415, https:// doi.org/10.3390/cli3020391.

— , K. De Ridder, S. Saeed, E. Brisson, F. Chatterjee, N. P. van Lipzig, B. Maiheu, and H. Hooyberghs, 2016: Assessing the current and future urban heat island of Brussels. Urban Climate, 15, 1-15, https://doi.org/10.1016/j.uclim.2015.11.008.

Lee, D. O., 1979: The influence of atmospheric stability and the urban heat island on urban-rural wind speed differences. Atmos. Environ., 13, 1175-1180, https://doi.org/10.1016/00046981(79)90042-8.

Lemonsu, A., R. Kounkou-Arnaud, J. Desplat, J. L. Salagnac, and V. Masson, 2013: Evolution of the Parisian urban climate under a global changing climate. Climatic Change, 116, 679692, https://doi.org/10.1007/s10584-012-0521-6.

Levermore, G., J. Parkinson, K. Lee, P. Laycock, and S. Lindley, 2018: The increasing trend of the urban heat island intensity. Urban Climate, 24, 360-368, https://doi.org/10.1016/j.uclim.2017.02.004.

Libert, J. P., J. Di Nisi, H. Fukuda, A. Muzet, J. Ehrhart, and C. Amoros, 1988: Effect of continuous heat exposure on sleep stages in humans. Sleep, 11, 195-209, https://doi.org/10.1093/ sleep/11.2.195.

Lo, Y. T. E., and Coauthors, 2019: Increasing mitigation ambition to meet the Paris Agreement's temperature goal avoids substantial heat-related mortality in U.S. cities. Sci. Adv., 5, eaau4373, https://doi.org/10.1126/sciadv.aau4373.

Magee, N., J. Curtis, and G. Wendler, 1999: The urban heat island effect at Fairbanks, Alaska. Theor. Appl. Climatol., 64, 39-47, https://doi.org/10.1007/s007040050109.

Mahlstein, I., G. Hegerl, and S. Solomon, 2012: Emerging local warming signals in observational data. Geophys. Res. Lett., 39, L21711, https://doi.org/10.1029/2012GL053952.

McCarthy, M. P., C. Harpham, C. M. Goodess, and P. D. Jones, 2012: Simulating climate change in UK cities using a regional climate model, HadRM3. Int. J. Climatol., 32, 1875-1888, https://doi.org/10.1002/joc. 2402.

Memon, R. A., D. Y. Leung, and C. H. Liu, 2009: An investigation of urban heat island intensity (UHII) as an indicator of urban heating. Atmos. Res., 94, 491-500, https://doi.org/10.1016/ j.atmosres.2009.07.006.

Met Office, 2019: Heatwave. Met Office, accessed 2019, https:// www.metoffice.gov.uk/weather/learn-about/weather/types-ofweather/temperature/heatwave.

Morice, C. P., J. J. Kennedy, N. A. Rayner, and P. D. Jones, 2012: Quantifying uncertainties in global and regional temperature change using an ensemble of observational estimates: The HadCRUT4 data set. J. Geophys. Res., 117, D08101, https:// doi.org/10.1029/2011JD017187.

Murphy, J., and Coauthors, 2009: UK Climate Projections Science Report: Climate change projections. Met Office Hadley Centre Tech. Rep., 190 pp.
— port. Met Office Tech. Rep., 191 pp., https://www.metoffice.gov. uk/pub/data/weather/uk/ukcp18/science-reports/UKCP18-Landreport.pdf.

Office for National Statistics, 2013: 2011 built-up areas-Methodology and guidance. U.K. Office for National Statistics Tech. Rep., 15 pp.

Oke, T. R., 1987: Boundary Layer Climates. 2nd ed. Taylor and Francis, 464 pp.

Oleson, K., 2012: Contrasts between urban and rural climate in CCSM4 CMIP5 climate change scenarios. J. Climate, 25, 13901412, https://doi.org/10.1175/JCLI-D-11-00098.1.

_ , G. B. Bonan, J. Feddema, and T. Jackson, 2011: An examination of urban heat island characteristics in a global climate model. Int. J. Climatol., 31, 1848-1865, https://doi.org/10.1002/joc.2201.

Porson, A., P. A. Clark, I. N. Harman, M. J. Best, and S. E. Belcher, 2010: Implementation of a new urban energy budget scheme in the MetUM. Part I: Description and idealized simulations. Quart. J. Roy. Meteor. Soc., 136, 1514-1529, https://doi.org/ 10.1002/qj.668.

Rainham, D. G., and K. E. Smoyer-Tomic, 2003: The role of air pollution in the relationship between a heat stress index and human mortality in Toronto. Environ. Res., 93, 9-19, https:// doi.org/10.1016/S0013-9351(03)00060-4.

Rogelj, J., and Coauthors, 2016: Paris Agreement climate proposals need a boost to keep warming well below $2^{\circ} \mathrm{C}$. Nature, 534, 631-639, https://doi.org/10.1038/nature18307.

Sachindra, D. A., A. W. Ng, S. Muthukumaran, and B. J. Perera, 2016: Impact of climate change on urban heat island effect and extreme temperatures: A case-study. Quart. J. Roy. Meteor. Soc., 142, 172-186, https://doi.org/10.1002/qj.2642.

Sarrat, C., A. Lemonsu, V. Masson, and D. Guedalia, 2006: Impact of urban heat island on regional atmospheric pollution. Atmos. Environ., 40, 1743-1758, https://doi.org/10.1016/j.atmosenv.2005.11.037.

Schlünzen, K. H., and S. I. Bohnenstengel, 2016: Socio-economic impacts-Urban climate. North Sea Region Climate Change Assessment, Springer International, 417-429, https://doi.org/ 10.1007/978-3-319-39745-0_15.

Smith, C. L., A. Webb, G. J. Levermore, S. J. Lindley, and K. Beswick, 2011: Fine-scale spatial temperature patterns across a UK conurbation. Climatic Change, 109, 269-286, https://doi.org/10.1007/s10584-011-0021-0.

Suomi, J., and J. Käyhkö, 2012: The impact of environmental factors on urban temperature variability in the coastal city of Turku, SW Finland. Int. J. Climatol., 32, 451-463, https:// doi.org/10.1002/joc.2277.

Tan, J., and Coauthors, 2010: The urban heat island and its impact on heat waves and human health in Shanghai. Int. J. Biometeor., 54, 75-84, https://doi.org/10.1007/s00484-009-0256-x.

Taylor, K. E., R. J. Stouffer, and G. A. Meehl, 2012: An overview of CMIP5 and the experiment design. Bull. Amer. Meteor. Soc., 93, 485-498, https://doi.org/10.1175/BAMS-D-11-00094.1.

Theeuwes, N. E., G. J. Steeneveld, R. J. Ronda, M. W. Rotach, and A. A. Holtslag, 2015: Cool city mornings by urban heat. Environ. Res. Lett., 10, 114022, https://doi.org/10.1088/17489326/10/11/114022.

UN DESA, 2018: $68 \%$ of the world population projected to live in urban areas by 2050, says UN. United Nations Department of Economic and Social Affairs, accessed 2019, https://www. un.org/development/desa/en/news/population/2018-revisionof-world-urbanization-prospects.html.

UN DESA/Population Division, 2018: World Urbanization Prospects 2018 - Country profiles. United Nations Department 
of Economic and Social Affairs, accessed 2019, https:// population.un.org/wup/Country-Profiles/.

UNFCCC, 2015: Adoption of the Paris agreement. United Nations Framework Convention on Climate Change Doc., $32 \mathrm{pp}$.

Vicedo-Cabrera, A. M., and Coauthors, 2018: Temperaturerelated mortality impacts under and beyond Paris Agreement climate change scenarios. Climatic Change, 150, 391-402, https:// doi.org/10.1007/s10584-018-2274-3.

Vukovich, F. M., W. J. King, J. W. Dunn III, and J. J. B. Worth, 1979: Observations and simulations of the diurnal variation of the urban heat island circulation and associated variations of the ozone distribution: A case study. J. Appl. Meteor., 18, 836-854, https://doi.org/10.1175/1520-0450(1979)018<0836:OASOTD $>2.0$. $\mathrm{CO} ; 2$.
Wilby, R. L., 2003: Past and projected trends in London's urban heat island. Weather, 58, 251-260, https://doi.org/10.1256/wea.183.02.

- 2008: Constructing climate change scenarios of urban heat island intensity and air quality. Environ. Plann., 35B, 902-919, https://doi.org/10.1068/b33066t.

Yamamoto, Y., 2006: Measures to mitigate urban heat islands. Quart. Rev. DC Nurses Assoc., 18, 65-83.

Yang, X., Y. Li, Z. Luo, and P. W. Chan, 2017: The urban cool island phenomenon in a high-rise high-density city and its mechanisms. Int. J. Climatol., 37, 890-904, https://doi.org/10.1002/joc.4747.

Zhang, N., X. Wang, and Z. Peng, 2014: Large-eddy simulation of mesoscale circulations forced by inhomogeneous urban heat island. Bound.-Layer Meteor., 151, 179-194, https://doi.org/ 10.1007/s10546-013-9879-x. 